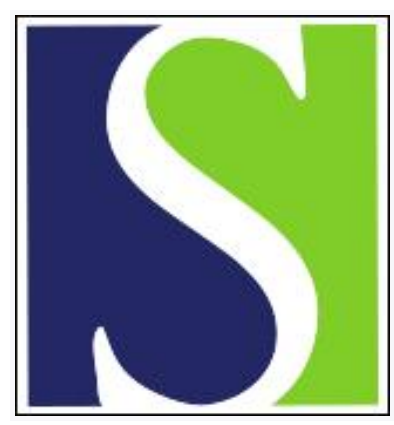

Scand J Work Environ Health 1997;23(1):48-53

https://doi.org/10.5271/sjweh.178

Issue date: Feb 1997

Relationship between asbestos bodies in sputum and the number of specimens

by Sulotto F, Capellaro E, Chiesa A, Villari S, Bontempi S, Scansetti G

Key terms: asbestos worker; low-medium exposure; probability of identification; several samples

This article in PubMed: www.ncbi.nlm.nih.gov/pubmed/9098912

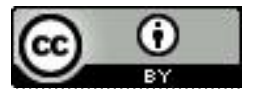




\title{
Relationship between asbestos bodies in sputum and the number of specimens
}

\author{
by Franca Sulotto, MD, ${ }^{1}$ Ermanno Capellaro, MD, ${ }^{1}$ Adriana Chiesa, MD, ${ }^{1}$ Sara Villari, MD, ${ }^{1}$ \\ Silvano Bontempi, MD, Giovanni Scansetti, $M D^{1}$
}

\begin{abstract}
Sulotto F, Capellaro E, Chiesa A, Villari S, Bontempi S, Scansetti G. Relationship between asbestos bodies in sputum and the number of specimens. Scand J Work Environ Health 1997;23(1):48-53.

Objectives This study investigated the relationship between asbestos body identification and the number of sputum specimens obtained from each subject.

Methods The presence of asbestos bodies in sputum was studied in 142 asbestos workers with former lowexposure levels; the number of specimens collected during 1-3 weeks varied from 2 to more than 4 . Furthermore the persistence of asbestos bodies in the sputum of 15 asbestos workers was studied during a longtime follow-up.

Results Asbestos bodies were present in at least 1 specimen in $44.4 \%$ of the 142 subjects. The cumulative percentage of asbestos body presence increased linearly, from $20 \%$ to $68 \%$, as the number of specimens increased.

Conclusions Five specimens did not seem to be sufficient to obtain satisfactory sensitivity in a group with low exposure to asbestos. Neither the type of exposure (to chrysotile only or to chrysotile plus amphibole) nor the presence of an asbestos-related disease clearly influenced the probability of finding asbestos bodies.
\end{abstract}

Key terms asbestos workers, low-medium exposure, probability of identification, several samples.

Asbestos bodies are observed in sputum in only about one-third of workers with definite asbestos exposure (1). The prevalence diminishes regularly from definite and heavy exposure $(38.4 \%)$ to possible or weak exposure $(2.9 \%)(2)$, and finally to the general population $(0.3 \%)$ (3). Thus the sensitivity of asbestos bodies in sputum as a marker of asbestos exposure is poor (4). However, according to some literature data (5), only $60 \%$ of asbestos workers are able to produce adequate sputum samples, and substantial daily variations can be observed for both asbestos body counts and macrophage counts in sputum specimens from the same subject. Therefore, negative results from a single sputum sample have little reliability, and several samples should be obtained from each subject (6).

There are only 2 reports which have studied the occurrence of asbestos bodies in relation to the number of sputum specimens. However, both include a small number of cases, and they use different protocols. The first (7) regarded 6 subjects examined twice a year, the total number of sputum specimens from each worker varying from 2 to 39 . The second (6) involved 20 people followed for 1 week with daily sputum examination; the number of adequate samples obtained from each subject varied from 3 to 7

Our report includes 2 sets of data. We obtained the first from 142 asbestos workers in order to assess the prevalence of asbestos bodies in sputum obtained in repeated examinations carried out during periods of 1 to 3 weeks. The second was carried out on a smaller sample (15 subjects) so that asbestos body presence in sputum could be examined during a lapse of several years.

The objective of the study was to determine the maximum asbestos body occurrence in a group of occupationally exposed workers according to the number of specimens collected. The effects of other factors (ie, type of exposure, presence of an asbestos-related disease) were also explored.

\section{Subjects and methods}

The first study was carried out from 1988 to 1993 on sputum specimens given by 590 asbestos workers fol-

1 Department of Traumatology, Orthopedics and Occupational Medicine, University of Turin, Italy.

Reprint requests to: Dr Franca Sulotto, Dipartimento di Traumatologia, Ortopedia e Medicina del Lavoro dell'Università di Torino, CTO, V Zuretti 29, 10126 Torino, Italy. 
lowed by the Occupational Health Institute of Turin (Italy). Spontaneous morning specimens were collected daily by encouraging each subject to repeat the procedure for as many days as possible. The collection lasted for three weeks or less for each subject. All the asbestos workers were taken into account, the only exclusion criterion being sputum inadequacy (228 subjects) or the production of less than 2 specimens (220 subjects). Visual inspection was used to assess the adequacy of the sputum specimen according to the size and number of plugs (at least a cumulative size of $4.5 \times 9 \mathrm{~mm}$ was estimated to be necessary). One hundred and forty-two subjects fulfilled the criteria, and 453 adequate specimens were obtained, 142 subjects giving 2 specimens, 101 giving 3 specimens, 33 giving 4 specimens, and 19 giving more than 4 specimens.

A further group of 15 asbestos workers was selected according to the availability of at least 2 sputum collections at different times, each consisting of a number of specimens varying from 1 to 5 . There was at least a 2-year interval between each examination. The followup occurred either for the renewal of a compensation claim or its reevaluation.

All the subjects in the two groups were interviewed by a physician as to work history, with specific questions on occupational asbestos exposure, smoking habits, and medical history. All the subjects had a physical examination, including a chest $\mathrm{X}$ ray and spirometry.

All the adequate samples of sputum were digested with $50-60 \mathrm{ml}$ of laundry bleach (chlorine $\geq 7 \%$ ). The cup was shaken for some minutes and then kept in a thermostatic oven at $40^{\circ} \mathrm{C}$ until complete clearing (48$72 \mathrm{~h}$ ); some hydrogen peroxide drops were added if necessary. The digestate was then filtered through a Millipore membrane filter (mixed esters of cellulose; diameter $25 \mathrm{~mm}$, pore size $0.8 \mu \mathrm{m}$ ). The filter was dried and cleared with acetone vapors. Observation was performed with the use of an optical microscope ( $\times 400$ magnification, phase contrast), and the result was expressed as asbestos bodies present or not.

Chi-square statistics with one degree of freedom were used to assess statistical significance.

Table 1 gives the age, gender, and smoking habit distributions of the current and former asbestos workers, as well as the asbestos-related diseases of the workers, and table 2 presents the data on the worker's exposures to asbestos. Almost all the subjects were men, and 75\% were former asbestos workers. Both the current and former workers had had a long exposure duration (table 2). Never smokers composed $28 \%$ of the group and

Table 1. General characteristics of the currently and formerly exposed groups.

\begin{tabular}{|c|c|c|c|c|c|c|c|c|c|c|c|c|c|c|c|c|c|c|c|c|c|}
\hline & \multirow{3}{*}{$\begin{array}{c}\text { Number } \\
\text { of } \\
\text { cases }\end{array}$} & \multirow{2}{*}{\multicolumn{2}{|c|}{$\begin{array}{c}\text { Age } \\
\text { (years) }\end{array}$}} & \multirow{2}{*}{\multicolumn{2}{|c|}{ Men }} & \multirow{2}{*}{\multicolumn{2}{|c|}{ Women }} & \multicolumn{6}{|c|}{ Smoking habit $(\mathrm{N}=138)$} & \multicolumn{8}{|c|}{ Asbestos-related disease } \\
\hline & & & & & & & & \multicolumn{2}{|c|}{ Smokers } & \multicolumn{2}{|c|}{$\begin{array}{c}\text { Never } \\
\text { smokers }\end{array}$} & \multicolumn{2}{|c|}{$\begin{array}{c}\text { Ex- } \\
\text { smokers }\end{array}$} & \multicolumn{2}{|c|}{ Absent } & \multicolumn{2}{|c|}{$\begin{array}{c}\text { Pulmonary } \\
\text { asbestosis } \\
\text { with or } \\
\text { without } \\
\text { pleural } \\
\text { changes }\end{array}$} & \multicolumn{2}{|c|}{$\begin{array}{l}\text { Lung } \\
\text { cancer }\end{array}$} & \multicolumn{2}{|c|}{$\begin{array}{c}\text { Pleural } \\
\text { meso- } \\
\text { thelioma }\end{array}$} \\
\hline & & Mean & SD & $\mathrm{N}$ & $\%$ & $\mathrm{~N}$ & $\%$ & $N$ & $\%$ & $N$ & $\%$ & $\mathrm{~N}$ & $\%$ & $N$ & $\%$ & N & $\%$ & $\mathrm{~N}$ & $\%$ & N & $\%$ \\
\hline $\begin{array}{l}\text { Currently } \\
\text { exposed } \\
\text { workers }\end{array}$ & 35 & 52 & 6 & 31 & 89 & 4 & 11 & 15 & 43 & 15 & 43 & 5 & 14 & 15 & 43 & 20 & 57 & - & - & - & - \\
\hline $\begin{array}{l}\text { Formerly } \\
\text { exposed } \\
\text { workers }\end{array}$ & 107 & 57 & 10 & 98 & 92 & 9 & 8 & 44 & 43 & 24 & 23 & 35 & 34 & 44 & 41 & 52 & 49 & 8 & 7 & 3 & 3 \\
\hline $\begin{array}{l}\text { Total } \\
\text { sample }\end{array}$ & 142 & 56 & 10 & 129 & 84 & 13 & 16 & 59 & 42 & 39 & 28 & 40 & 30 & 59 & 42 & 72 & 51 & 8 & 5 & 3 & 2 \\
\hline
\end{tabular}

Table 2. Exposure characteristics of the currently and formerly exposed groups.

\begin{tabular}{|c|c|c|c|c|c|c|c|c|c|c|c|c|}
\hline & \multirow{2}{*}{\multicolumn{2}{|c|}{$\begin{array}{l}\text { Exposure } \\
\text { (years) }\end{array}$}} & \multicolumn{6}{|c|}{ Level of exposure } & \multicolumn{4}{|c|}{ Type of exposure } \\
\hline & & & \multicolumn{2}{|c|}{ Low } & \multicolumn{2}{|c|}{ Medium } & \multicolumn{2}{|c|}{ High } & \multicolumn{2}{|c|}{ Chrysotile } & \multicolumn{2}{|c|}{$\begin{array}{l}\text { Chrysotile } \\
\text { and } \\
\text { amphiboles }\end{array}$} \\
\hline & Mean & SD & $N$ & $\%$ & $N$ & $\%$ & N & $\%$ & $\mathrm{~N}$ & $\%$ & $N$ & $\%$ \\
\hline $\begin{array}{l}\text { Currently exposed } \\
\text { workers }\end{array}$ & 18 & 9 & 15 & 43 & 12 & 34 & 8 & 23 & 22 & 63 & 13 & 37 \\
\hline $\begin{array}{l}\text { Formerty exposed } \\
\text { workers }\end{array}$ & 14 & $11^{\mathrm{a}}$ & 46 & 43 & 36 & 34 & 25 & 23 & 52 & 48 & 50 & 52 \\
\hline Total sample & 15 & 10 & 61 & 43 & 48 & 34 & 33 & 23 & 79 & 56 & 63 & 44 \\
\hline
\end{tabular}

a This group had left exposed work an average of 15 (SD 11) years of ago. 
$72 \%$ were smokers (42\% current smokers and $30 \%$ exsmokers).

The subjects were classified according to intensity and type of exposure (table 2). The criteria were selfreported work history, one of the authors' knowledge on the chrysotile quarry at Balangero (Italy) and on almost all asbestos manufacturing in Piedmont (Italy), and data on air fiber concentration for several tasks (8).

The low-exposure group had had tasks with an airborne fiber (f) concentration of less than $2-3 \mathrm{f} / \mathrm{ml}$. Medium exposure involved tasks with a fiber concentration between 3 and $10 \mathrm{f} / \mathrm{ml}$. Heavy exposure consisted of work with a fiber concentration of more than $10 \mathrm{f} / \mathrm{ml}$. Workers in the steam electric generating plant and the foundry, the railway and paper manufacturing workers, the plastic insulation and fibrous plasterers, and the sound deadening workers were considered to have low exposure. The medium exposure group comprised chrysotile miners and millers and brake lining workers. Asbestoscement and textile workers and insulation workers were heavily exposed. Seventy-seven percent of the entire cohort was grouped into the low or medium-exposed categories.

The definition of exposure to either chrysotile or chrysotile plus amphibole derived largely from direct knowledge of the work processes. The type of exposure was judged as follows. All the workers in the mediumexposure group were exposed to chrysotile, as were the paper manufacturers, plastic insulators, fibrous plasterers, and sound deadening workers of the low-exposure group. All of the heavily exposed group and the railway and foundry workers and the steam electric generating plant workers were exposed to both chrysotile and amphibole asbestos. On the basis of this classification, exposure to chrysotile only was presumed for $56 \%$ of the subjects, and $44 \%$ was exposed to both chrysotile and

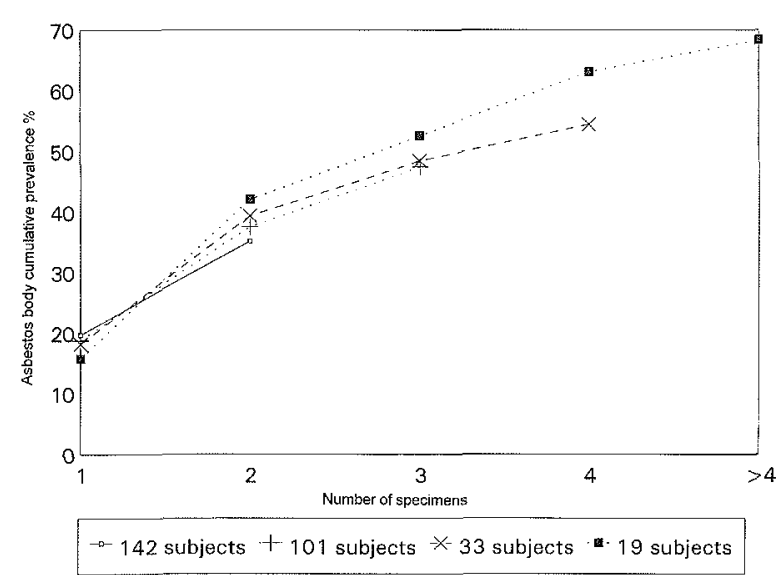

Figure 1. Cumulative prevalence of asbestos bodies in sputum according to the number of specimens obtained from the subjects of the 4 subgroups. amphibole asbestos. More subjects were exposed to chrysotile only in the subgroup of currently exposed workers than in that with former exposure.

\section{Results}

Asbestos-related diseases were present in $58 \%$ of the subjects.

The lowest proportion of asbestos diseases (any type) was observed among the subjects with low exposure (48\%); on the contrary, among the subjects with medium or high exposure, the proportion was higher and similar (69\% and 64\%, respectively).

Asbestos bodies were observed in 94 smears (21\% of the total), being present in at least 1 specimen of $44.4 \%$ of the subjects.

An exposure intensity score was obtained by multiplying each subject's exposure years by 1 for low exposure, 2 for medium exposure or 3 for heavy exposure. Asbestos bodies were present in the sputum of $39 \%$ of those with a score of $\leq 21$ ( 69 subjects), in the sputum of $50 \%$ with a score of $21-40$ (40 subjects), in the sputum of $48 \%$ with a score of $>40$ (33 subjects). When the subjects with a score of $1-20$ were compared with those with a score of $>20$, the difference was not significant (chi-square 1.107, not significant).

Figure 1 shows the cumulative prevalence of the asbestos bodies in the sputum; the sample was subdivided into 4 groups according to the number of specimens collected. The asbestos body prevalence of each subgroup, after the first specimen collection, was low and similar, varying from $15.8 \%$ to $19.7 \%$. The prevalence increased constantly as the number of specimens increased, reaching $68 \%$ for the 19 subjects with more than 4 specimens. The trend was similar in the 4 subgroups, at least up to the collection of 4 specimens.

The subdivision of the entire group into those exposed only to chrysotile and those exposed to both chrysotile and amphibole did not change the asbestos body prevalence trend. Even when the subgroups with less than 10 subjects were excluded, the groups remained small, and this result may well explain the relatively irregular trend. (See figure 2.)

The same phenomenon applies to the asbestos body prevalence of the 4 subgroups in the presence of asbestos-related diseases (figure 3 ).

Figure 4 compares the cumulative asbestos body prevalence of the subgroup with more than 4 specimens with that of McDonald's group (6), for which 5 specimens had been collected. This group was characterized by a higher asbestos body prevalence ( $83.3 \%$ ), which was evident from the first test $(55.5 \%)$, and by the fact that the occurrence did not increase after the third speci- 

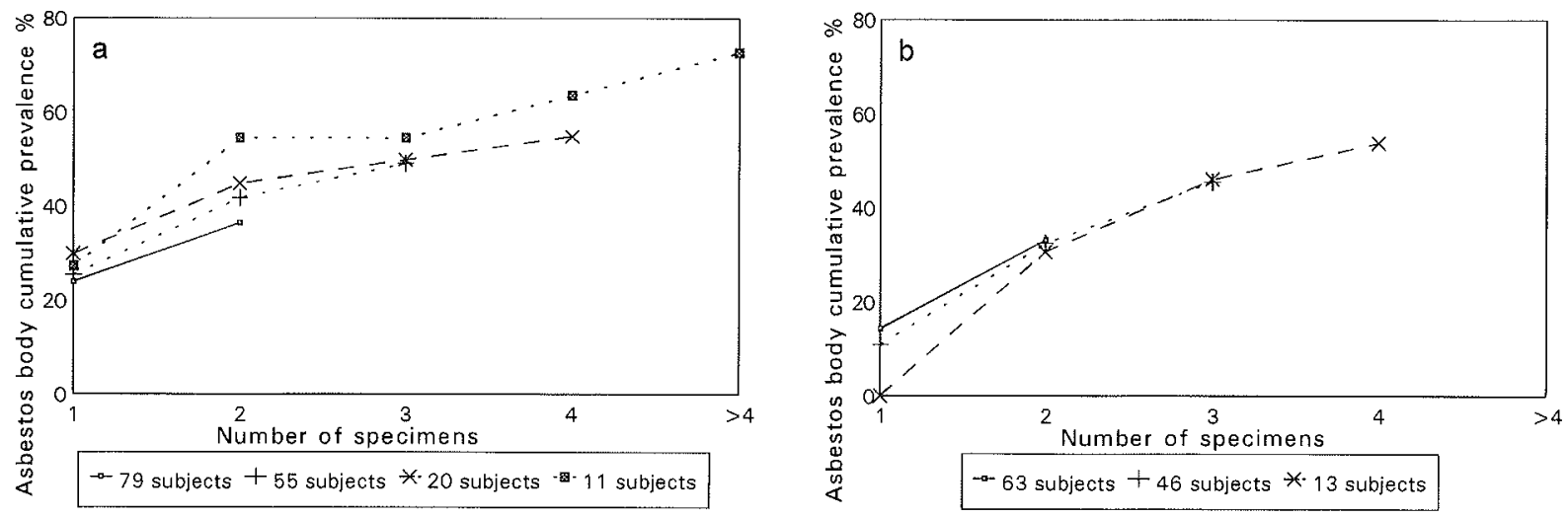

Figure 2. Cumulative prevalence of asbestos bodies in sputum according to the number of specimens obtained and to the type of exposure in the 4 subgroups. Only the subgroups with more than 10 subjects have been included. $(a=$ chrysotile exposure, $b=$ chrysotile-amphibole exposure)
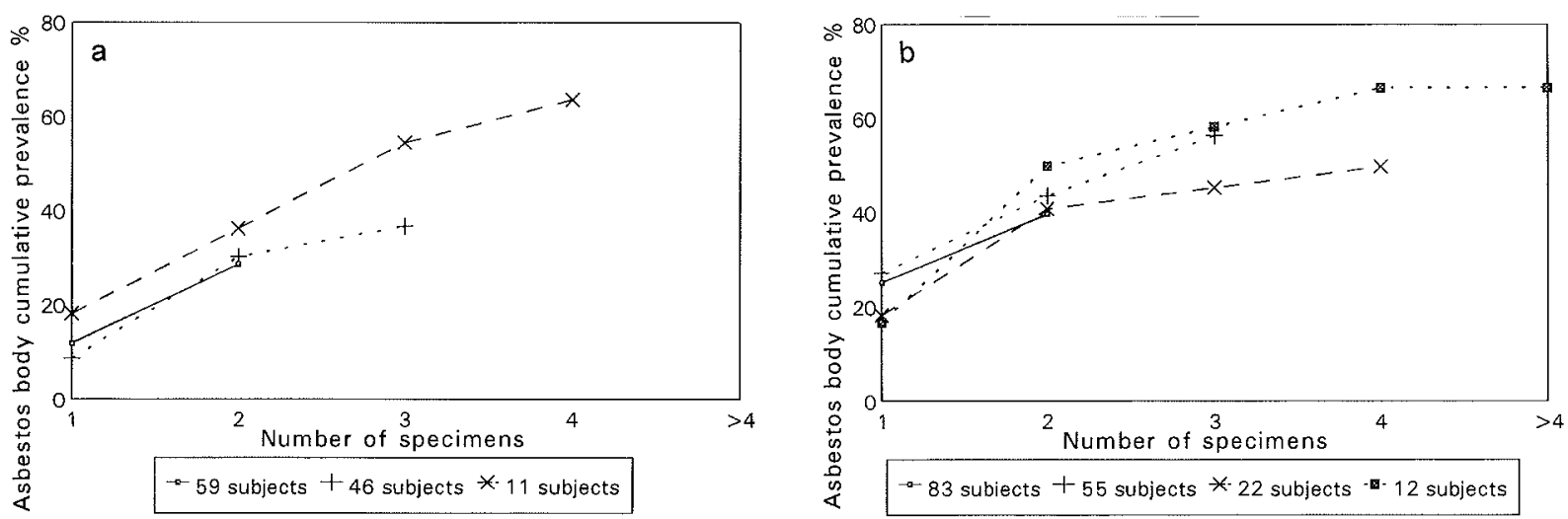

Figure 3. Cumulative prevalence of asbestos bodies in sputum according to the number of specimens executed and to the presence of an asbestosrelated disease in the 4 subgroups. Only the subgroups with more than 10 subjects have been included. ( $a=$ no asbestos diseases, $b=$ asbestos diseases)

men, whereas, in our group, the trend continued to increase.

Figure 5 gives the history of asbestos body presence in sputum taken in a random examination of 15 asbestos workers (2nd study group) over time.

Seven of 9 patients with asbestosis had at least 1 positive finding during the follow-up. There was only 1 positive case among the disease-free subjects.

There were no differences in asbestos body presence between the workers exposed to chrysotile and those exposed to chrysotile plus amphibole (5 of 9 and 3 of 6 , respectively).

There was a discrepancy in the results for the specimens collected during exposure and those collected after withdrawal. Among the former, 5 of $6(83 \%)$ were negative, whereas among the latter only 16 of $26(61.5 \%)$ were negative.

No relationships were observed between the presence of asbestos bodies and the duration of exposure or the time elapsed since withdrawal, either among the chrysotile or the chrysotile-amphibole workers.

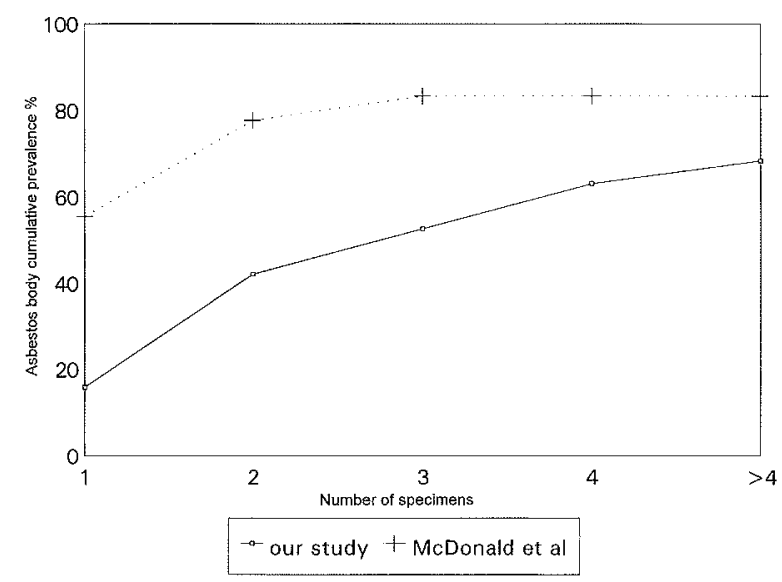

Figure 4. Cumulative prevalence of asbestos bodies in sputum according to the number of specimens obtained in 2 groups of asbestos workers (our study and McDonald's group) with 5 specimens.

\section{Discussion}

No sputum sample was obtained for $38.6 \%$ of the asbestos workers, a percentage similar to that obtained by 


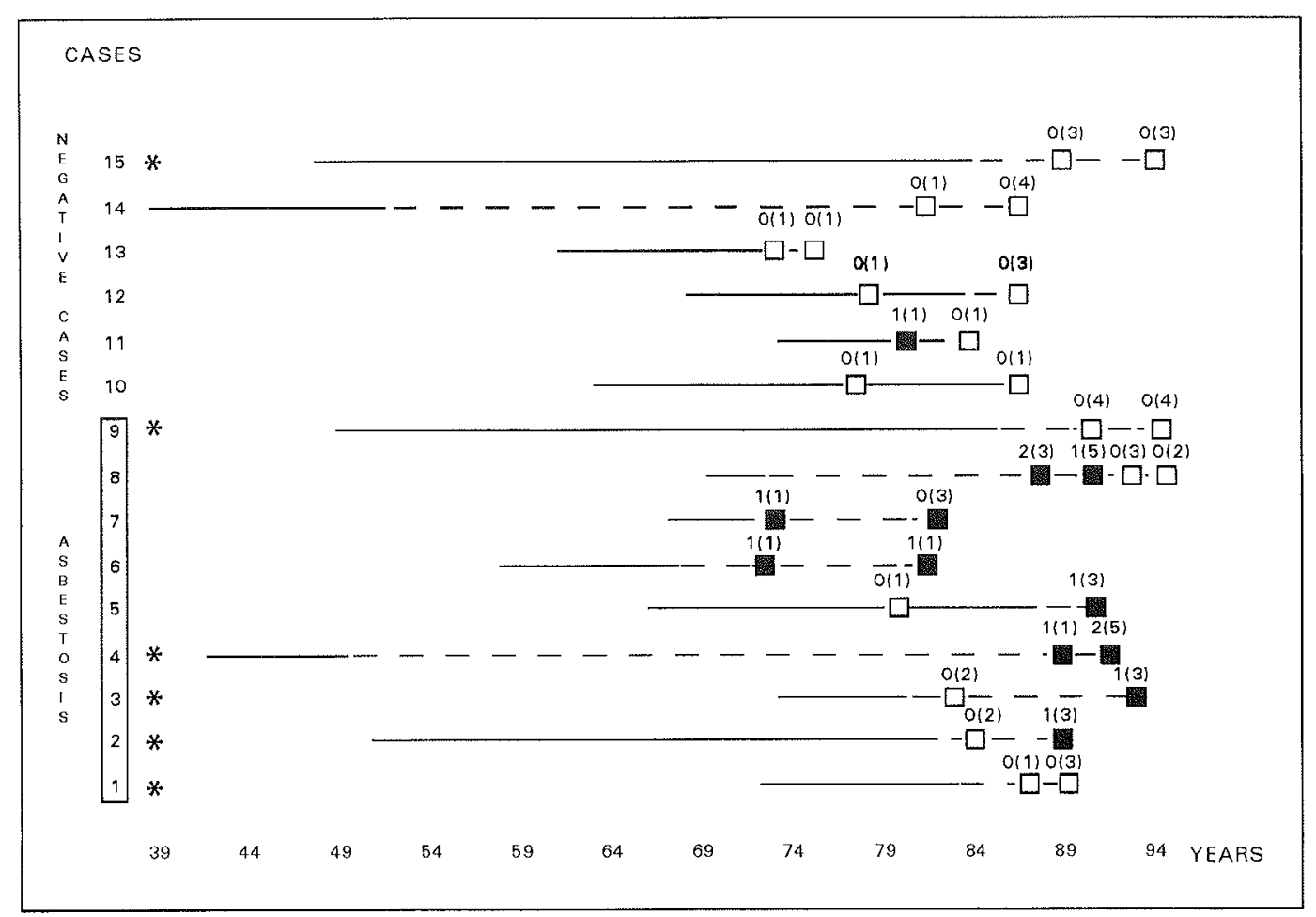

Figure 5. History of asbestos body presence in sputum over time for 15 asbestos workers. Low exposure cases: 4 (a railway worker), 9 and 15 (foundry workers); medium exposure cases: 2 and 14 (chrysotile miners), $5-8,10,11$ and 13 (brake lining workers); heavy exposure cases: 3 (textile workers), 1 and 12 (insulation workers). Cases $1-9$ had pulmonary asbestosis and cases $10-15$ were disease free. $\left({ }^{*}=\right.$ chrysotile-amphibole exposure,- years of exposure, $----=$ years of exposure withdrawal, $=$ asbestos body presence, $\square=$ no asbestos bodies, number over the square $=$ number of positive specimens, number in parentheses $=$ number of specimens collected)

Xaubet et al (5); however it is not clear if this result was due to the worker's inability to produce an adequate sputum sample or to poor compliance. Many factors may have influenced this result, and they should be clarified.

The group of 142 workers had a relatively homogeneous exposure intensity, estimated as low-medium. This assumption, based on job history, was confirmed by the low asbestos body occurrence in the first sputum specimen (only $20 \%$ of the total sample) and by the similar occurrence of asbestos bodies in samples from those with a respectively low and high score of exposure intensity.

A bias of the study may be the fact that asbestos bodies in sputum were not counted. Therefore it was impossible to establish their concentration. However we know that even 1 asbestos body in sputum is suggestive of considerable asbestos exposure (7) and reflects a significant residual load of asbestos within the lung (about 10000 asbestos bodies per gram of dry lung) (9). Therefore we suggest that our qualitative method of analysis did not interfere substantially with the results.

Repeating the test increased the cumulative asbestos body finding almost linearly up to 5 consecutive sputum samples. On the contrary, in McDonald's study (6), the maximum cumulative number of asbestos bodies in- creased only through the first 3 tests. The difference between the 2 studies can be explained by the heavy current asbestos exposure of the subjects in McDonald's cohort (vermiculite miners). In a group with lower past exposure, such as ours, 5 sputum examinations may not be enough to reach the highest asbestos body prevalence. Unfortunately, in epidemiologic surveys, patient compliance to a protocol entailing 7 to 10 sputum collections is difficult to achieve.

However, a protocol with more than 7 to 10 sputum collections would probably be of little help, as there are always some cases, even in heavy exposure groups, in which sputum specimens are inadequate for asbestos body detection. Moreover, no asbestos bodies were identified in sputum samples from subjects with less than 100 asbestos bodies per gram of wet lung tissue (1000 per gram of dry tissue being considered the cutoff for occupational exposure), which was verified in a subject providing 20 sputum specimens (7).

In our study the finding of asbestos bodies in sputum was not clearly connected to the presence of an asbestosrelated disease, even though it was hypothesized for a small group of 15 workers controlled over long periods of time. The same applies for those exposed also to amphibole. This finding is not in agreement with the 
faster clearance of chrysotile from the lung (10), and specifically not with our findings in another group of 220 asbestos workers with high exposure (11). The different results in the present study may be attributed to various factors. First, our definition of the type of exposure was based on anamnestic evaluation and not on analytical findings [such as transmission electron microscopy (TEM) of the cores], or on directly measured air concentrations. Second, 31 of the 63 amphibole-exposed subjects had a low exposure level. Moreover, asbestos bodies in the sputum were reported as present or absent, and thus we do not have quantitative data, which may have shown variations according to exposure type.

Asbestos body presence did not seem to be constant over long periods of observation. (See the results for the small group of 15 cases.) These findings agree with the hypothesis that the presence of asbestos bodies in sputum is independent of the time elapsed from cessation of exposure $(6,12)$ and that asbestos body count in sputum does not reliably reflect past exposure level (6). As in the present study, Roggli et al (7) did not find a relationship between asbestos body counts in sputum and type of job or length of employment. However, McDonald et al (6) found such associations on a small level.

In our study we did not compare the probability of asbestos body finding in sputum and bronchoalveolar lavage fluid, a problem which has been debated in another of our reports (in press). The concordance between the two methods seems weak (being present for only $56.9 \%$ of the cases) and suggests that the 2 methods of asbestos body detection do not overlap, but may be complementary, both being useful in increasing the probability of asbestos body detection.

In conclusion, our study confirms the utility of obtaining several specimens from each subject in order to increase the probability of asbestos body identification. Many factors (ie, level, duration, type and intensity of exposure and the ability to produce adequate sputum samples) may interfere with the results, particularly in cases of former asbestos exposure and, in general, low exposure, for which more than 5 specimens are advisable. Further studies on homogeneous groups as to type and level of exposure and the availability of $7-10 \mathrm{spec}-$ imens for each subject may be useful. At present, studies are being carried out on the TEM identification of asbestos body cores in a new asbestos worker group, the results of which will be presented in the near future.

\section{References}

1. Modin BE, Greenberg SD, Buffler PA, Lockhart JA, Seitzman LH, Awe RJ. Asbestos bodies in a general hospital/clinic population. Acta Cytol 1982;26:667_70.

2. Scansetti G, Pira E, Botta GC, Turbiglio M, Piolatto G. Asbestos exposure in a steam-electric generating plant. Ann Occup Hyg 1993;37:645-53.

3. Anonymous. Biological indicators and their clinical significance in persons exposed to mineral fibres: report of a workshop held in Japan, 24-25 November 1991. Br J Ind Med 1991;50:412-7.

4. Greenberg SD. Cytopathology and asbestos-associated diseases. In: Roggli VL, Greenberg SD, Pratt PC, editors. Pathology of asbestos-associated diseases. Boston (MA): Boston Little Brown and Company, 1992:223-56.

5. Xaubet A, Rodriguez-Roisin R, Bombi JA, Marin A, Roca J, Agusti-Vidal A. Correlation of bronchoalveolar lavage and clinical and functional findings in asbestosis. Am Rev Respir Dis 1986;133:848-54.

6. McDonald JC, Sebastien P, Case B, McDonald AD, Dufresne A. Ferruginous body counts in sputum as an index of past exposure to mineral fibres. Ann Occup Hyg 1992;36:27182.

7. Roggli VL, Greenberg SD, McLarty JW, Hurst GA, Hieger RR, Farley ML, et al. Comparison of sputum and lung asbestos body counts in former asbestos workers. Am Rev Respir Dis 1980;122:941-5.

8. Scansetti G, Piolatto G, Pira E. Il rischio da amianto oggi [Asbestos risk today]. Turin (Italy): Regione Piemonte, 1985:152-61.

9. Sébastien P, Bignon J, Barris YI, Awad L, Petit G. Ferruginous bodies in sputum as an indication of exposure to airborne mineral fibers in the mesothelioma villages of Cappadocia. Arch Environ Health 1984:39:18-23.

10. Holt PF. Inhaled dust and disease. Chichester: Wiley and Sons, 1987:111-25.

11. Scansetti G, Chiesa A, Capellaro E, Villari S, Sulotto F. Asbestos bodies in sputum of asbestos exposed workers. Med Lav 1996;87:283-8.

12. McLarty JW, Greenberg SD, Hurst GA, Spivey CG, Seitzman LH, Hieger LR, et al. The clinical significance of ferruginous bodies in sputa. J Occup Med 1980;22:92-6.

Received for publication: 15 February 1996 